services, which are integrated into the respective fields of adult and childhood medical studies, and (b) non-personal services (including environmental and occupational health), which constitute the major subjects at the undergraduate faculties of hygiene. Hygienists staff the sanitary and epidemiology stations and may further specialize in nutrition, municipal hygiene, and industrial hygiene. It appears that, in many respects, the medical hygienists of the U.S.S.R. fill the posts usually occupied by sanitary engineers in other countries.

Scientific research is a most important function of all medical units in the U.S.S.R. Research is planned and co-ordinated, however, and it includes basic, clinical, applied and operational aspects. The system of special research institutes and advisory councils, together with the hierarchical structure of research units, ensures the proper utilization of funds and directs research towards the more pressing problems of the nation.

All heads of divisions and departments of the medical services are medical graduates. Even those departments which deal with sanitary engineering, nursing and para-medical training are headed by doctors. There is no nursing council as such, and the post of sanitary engineer is non-existent. Engineers are attached to departments dealing with buildings and construction, but their task is that of a constructional engineer rather than of a specialized sanitary engineer. The lay sanitarian or sanitary inspector, as known in other countries, is unknown in the U.S.S.R., and his task is performed by doctors, assisted by feldschers. Nor are the posts of social workers and social anthropologists known in the U.S.S.R.

The number of doctors in the U.S.S.R. is high, there being about one doctor to every 570 of the population, and in some regions, such as Georgia, as many as 1 in 400 . The ratio of male to female doctors is about $50: 50$, but in some areas 70 per cent of practising doctors are women. The total number of medical graduates in the U.S.S.R. in 1957 was 360,000 , a striking increase over the figure for 1913, which was 23,000 . It is estimated on the basis of existing facilities for medical education that, by the end of the new 'seven-year' plan in 1965, there will be 490,000 doctors in the country, which will give a ratio of one doctor to every 460 inhabitants.

There were also 99,921 mid-wives working in the U.S.S.R. in 1957, as well as 71,151 feldscher-midwives and 14,714 feldschers. It is estimated that by 1965 there will be $1,470,000$ qualified nurses in the country, or 3 qualified nurses to every doctor.

\title{
BIOLOGICAL EFFECTS OF ATOMIC RADIATION
}

$\mathrm{I}^{\mathrm{N}}$

1956, a report with this title was published by the U.S. National Academy of Sciences. It contained the findings and recommendations of six committees dealing with genetics, pathology, meteorology, oceanography and fisheries, agriculture and food supplies, and disposal and dispersal of radioactive wastes. During the intervening years these committees have continued to collect information in their separate fields, and they have now published their findings and conclusions in the same form as before*. The report is shorter than the first one, in which much space had to be devoted to explanations of fundamental scientific facts and principles. The presentation is again admirably clear and as free from technicalities as possible; the main points are condensed into a separate, concise and easily understood "Report to the Public". Several appendixes bring more detailed information and calculations; technical reports are in preparation. The following are some of the more important statements.

At present, delayed fall-out from the stratospheric reservoir is the major source of airborne artificial radioactivity and will remain so unless large-scale testing is resumed. There is a non-uniform distribution of strontium-90 in fall-out, with a maximum at lat. $40-50^{\circ} \mathrm{N}$. Fall-out is greatest in spring and is mostly brought down by precipitation. The half-residence time of radioactive debris in the troposphere is about 2-4 weeks ; in the stratosphere it depends on the latitude at which the debris was injected. For injections in equatorial regions, the half-residence time is $2-5$ years; for injections in temperate $a$ : $d$ polar zones it is less than 1 year. If

- National Aca demy of Sciences-National Research Council. Th Biological Effects of Atomic Radiation: Summary Reports from a Study by the National Academy of Sciences. Pp. xi +90 . A Repor to the Public on the Biological Effects of Atomic Radiation based on the 1960 Summary Reports of the National Academy of Sciences Committee on the Biological Effects of Atomic Radiation. Pp. iii +19. (Washington, D.C.: National Academy of Sciences-National Research Council, 1960.) there are no further additions to the atmospheric burden, most of the remaining radioactivity in the atmosphere will have settled down by $1962-63$; the ground concentration will then be about twice that of November 1958. It is certain that all living things, man included, now have a radioactive body burden higher than in the pre-atomic era, and although the present levels in foodstuffs are low, the cumulative and retained isotope burden in man must be considered.

The estimate of genetical radiation damage has gone up as a result of the recent increase in fall-out and the previously unconsidered contribution to it of carbon-14. On the other hand, the finding that in spermatogonia and oocytes-but not in mature spermatozoa - of mice and Drosophila a given dose of radiation produces fewer mutations when administered at low than at high intensity may mean that previous estimates of genetical radiation damage have erred on the high side. In the absence of more information on the effects of dose-rate and dosefractionation, the committee continues to recommend that for the general population the average gonadal dose accumulated during the first 30 years of life should not exceed $10 \mathrm{r}$. of man-made radiation, and should be kept as far below this as practicable. In human tissue cultures, doses of $25 \mathrm{r}$. produce detectable chromosome breakage in a significant proportion of cells. A slight, but statistically significant, deviation from the normal sex-ratio was observed among children of survivors of the Japanese atom bomb explosion; possibly this might be due to the action of sex-linked mutations affecting prenatal viability. In animals, a shortening of life-span through radiation has been observed not only for the irradiated individuals themselves, but also for their progeny. In man, shortening of life has not been demonstrated after small doses, but is expected to occur after substantial doses of whole-body irradiation. Part of 
this expected decrease in life-span will be due to leukæmia, which is known to affect over-exposed individuals with more than average frequency. The question whether diagnostic $\mathrm{X}$-radiation during pregnancy increases the incidence of leukæmia in the children cannot be decided on the available evidence. Neither can it be decided whether there is a lower threshold to the production of tumours and leukæmia by irradiation, but the sub-committee dealing with hæmatological effects thinks it prudent to assume that for leukæmia no threshold exists. Mammalian embryos are readily affected by low doses of ionizing radiation. One of the most sensitive known indicators of chronic biological damage is the gradual reduction in number, motility and viability of sperm, resulting from small chronic radiation over-exposure. In dogs, effects on sperm have been observed at chronic doserates of only ten times the maximum permissible value for human occupational exposure.

\section{MODERNIZATION OF THE STOCKHOLM CYCLOTRON}

$I^{\mathrm{N}}$ 'two papers published during 1952, H. Atterling and $G$. Lindström described the initial performance of the fixed frequency $225-\mathrm{cm}$. cyclotron at the Nobel Institute of Physics, Stockholm (Arkiv for Fysik, 4, $559 ; 1952$, and Nature, 169,$432 ; 1952)$. A more detailed description of the machine, which has operated reliably and stably for several years producing internal beams of protons, deuterons, alphaparticles and heavy ions (carbon, nitrogen, oxygen and neon ions), is given in two recent articles in Arkiv for Fysik $(15,483$ and $531 ; 1959)$. The oscillator-frequency used recently is $8.1 \mathrm{Mc} . / \mathrm{s}$. and with this frequency the machine accelerates ions to a nominal energy of about $11 \mathrm{MeV}$. per nucleon at a radius of $90 \mathrm{~cm}$. Internal beam currents of approximately $300 \mu \mathrm{mp}$. of $22-\mathrm{MeV}$. deuterons are obtained.

In March 1958, the cyclotron was shut down and taken to pieces for remodelling. Previously it had been run exclusively with internal beams, but when the dees were designed provision was made for the subsequent mounting of an internal d.c.-deflector in one of the dees and during the reassembly of the dees the deflector is being installed. mentioned.
Considerable space is devoted to recommendations for future research, especially in the field of genetics. The need for basic research is stressed, and the relevance of mutation research on all forms of life, including bacteria and viruses, is pointed out. On the other hand, attention is directed to problems that arise in human populations and have no counterpart in animal societies. Thus: "human society depends upon a diversity of performance among its members and on very high mental qualities among a few of them. A human civilization might collapse by becoming qualitatively inadequate, even though reproductive selection of certain kinds were acting at high intensity and the number of individuals in the population remained at a level that was previously optimal". These sentences have an obvious relevance to the questions discussed in the leading article "Evolution of Mankind" in Nature of February 13. C. Aumrbach

The machine is housed in an underground hall, resting directly on rock and surrounded on all sides by rock, clay and earth. On the top it is shielded by a water pond two metres deep. The control room is in a three-storey building above ground, and the connexion between the building and the cyclotron hall is via a stairway or a lift to the bottom of a shaft from which a corridor leads to the hall. A removable $150-\mathrm{cm}$. concrete thick wall partly closes the corridor, leaving an opening $140 \mathrm{~cm}$. broad which can be closed by a concrete door weighing 35 tons. The first article contains full details together with drawings and photographs of the building; the magnet ; the radiofrequency tank and dee systems; and the ionsource of the cyclotron. In the second article the techniques used in the work on heavy-ion acceleration in the cyclotron together with some results of the investigation of the energy-distribution for ${ }^{12} \mathrm{C}^{1+}$ ions are outlined. It is shown that the distribution contains a low-energy component in addition to the higher-energy peak of the ions. Other applications of the accelerated heavy-ions, in particular for the production of transuranium elements, are briefly

\section{DAILY FOOD CONSUMPTION BY SOUTH AFRICAN UNIVERSITY STUDENTS}

$I^{\mathrm{T}}$ has been the practice of the Department of Physiology of the University of the Witwatersrand to request students, as part of their physiological training, to keep a daily record of their food consumption over a defined period of time. The records from one year's class form the basis of a preliminary report by Sonia E. Walker ; but it is hoped that data accumulating over several years will afterwards be analysed, and will give some indication of the diet. ary trends in this student section of the community (South African J. Med. Sci., 24, December, 1959).

The food consumption-levels of the students investigated are similar to those reported from other parts of the world. In a survey of dietary levels of households in the United States, the average consumption per person per day was found to be $2,760-3,260$ calories, 87-115 gm. protein and 133-161 gm. fat. The share of total calories derived from carbohydrate was 43 per cent, from protein 13 per cent, and, from fat, 44 per cent. A more recent report based on the estimation of apparent civilian consumption per capita per day in the United States gives mean daily intakes of 3,160 cal., $96 \mathrm{gm}$. protein, $378 \mathrm{gm}$. carbohydrate and $144 \mathrm{gm}$. fat. In the United Kingdom a similar estimation of food consumption per head of civilian. population per day gave 2,890 cal., $380 \mathrm{gm}$. carbohydrate, $112 \mathrm{gm}$. fat, and $90 \mathrm{gm}$. protein. 